\title{
Aberrant expression of RABIA in human tongue cancer
}

\author{
K Shimada', K Uzawa ${ }^{*, 1,3}$, M Kato ${ }^{2}$, Y Endo', M Shiiba', H Bukawa ${ }^{3}$, H Yokoe ${ }^{3}$, N Seki ${ }^{2,4}$ and H Tanzawa ${ }^{1,3,4}$ \\ 'Department of Clinical Molecular Biology, Graduate School of Medicine, Chiba University, I-8-I Inohana, Chuo-ku, Chiba 260-8670, Japan; \\ ${ }^{2}$ Department of Functional Genomics, Graduate School of Medicine, Chiba University, I-8-I Inohana, Chuo-ku, Chiba 260-8670, Japan; ${ }^{3}$ Division of Oral \\ Surgery, Chiba University Hospital, I-8-I Inohana, Chuo-ku, Chiba 260-8670, Japan; ${ }^{4}$ Center of Excellence (COE) Program in the 2 Ist Century, Graduate \\ School of Medicine, Chiba University, I-8-I Inohana, Chuo-ku, Chiba 260-8670, Japan
}

\begin{abstract}
This study was designed to identify specific gene expression changes in tongue squamous cell carcinomas (TSCCs) compared with normal tissues using in-house cDNA microarray that comprised of 2304 full-length cDNAs from a cDNA library prepared from normal oral tissues, primary oral cancers, and oral cancer cell lines. The genes identified by our microarray system were further analysed at the mRNA or protein expression level in a series of clinical samples by real-time quantitative reverse transcriptasepolymerase chain reaction ( $\mathrm{RRT}-\mathrm{PCR}$ ) analysis and imuunohositochemistry. The microarray analysis identified a total of I 6 genes that were significantly upregulated in common among four TSCC specimens. Consistent with the results of the microarray, increased mRNA levels of selected genes with known molecular functions were found in the four TSCCs. Among genes identified, Rab / a, a member of the Ras oncogene family, was further analysed for its protein expression in 54 TSCCs and I 3 premalignant lesions. We found a high prevalence of Rab I A-overexpression not only in TSCCs (98\%) but also in premalignant lesions (93\%). Thus, our results suggest that rapid characterisation of the target gene(s) for TSCCs can be accomplished using our in-house cDNA microarray analysis combined with the qRT-PCR and immunohistochemistry, and that the Rab IA is a potential biomarker of tongue carcinogenesis. British Journal of Cancer (2005) 92, 1915-1921. doi:I0.1038/sj.bjc.6602594 www.bjcancer.com
\end{abstract}

Published online 3 May 2005

(c) 2005 Cancer Research UK

Keywords: tongue squamous cell carcinoma; in-house cDNA microarray; gene expression profiling; Rab/a gene

Squamous cell carcinoma (SCC) is by far the most common malignant neoplasm of the oral cavity, representing approximately $90 \%$ of all oral cancers. Although it occurs at various oral regions, the tongue is one of the most frequent sites (Boyle et al, 1992; Perkin et al, 1993). A number of aetiologic factors have been implicated in the development of oral SCCs, such as the use of tobacco, alcohol, or the presence of incompatible prosthetic materials (Mashberg et al, 1993; Macfarlane et al, 1995). However, some patients without those risk factors actually develop tumours of the tongue, and there are individual variations in the progression or differentiation of the cancer, which suggests that host susceptibility may play a role. In this context, molecular alterations in a number of oncogenes and tumour suppressor genes associated with the development of tongue SCC (TSCC) could be important clues for addressing these problems (Fearon and Vogelstein, 1990; Marshall, 1991).

Recent reports have documented alterations of a few oncogenes and tumour suppressor genes in oral cancer including TSCC (Scully et al, 2000), but the molecular and genetic basis of tongue carcinogenesis still remains largely unknown and global gene expression has not been clarified. In recent years, the cDNA microarray system has facilitated the simultaneous investigation of a large set of genes or gene clusters, allowing analysis of even complex processes in a short time (Schena et al, 1995; DeRisi et al, 1996). We recently developed an in-house cDNA microarray

*Correspondence: Dr K Uzawa; E-mail: uzawak@faculty.chiba-u.jp Received 27 October 2004; revised 18 February 2005; accepted 24 March 2005; published online 3 May 2005 derived from our oligo-capped human oral cancer cDNA library (Moriya et al, 2003). This microarray system successfully identified genes that are differentially expressed in common in oral SCCderived cell lines compared with those in normal oral tissues, indicating that this system may be a powerful prioritisation tool in the search for disease significance.

In the present study, we attempted to identify target gene(s) for TSCC using our cDNA microarray. In addition, expression states of the mRNA and protein of candidate genes were evaluated further by real-time quantitative reverse transcriptase-polymerase chain reaction ( $\mathrm{qRT}-\mathrm{PCR}$ ) analysis, or both and semiquantitative immunohistochemistry in a large series of tumours of the tongue and premalignant lesions of the tongue (tongue leukoplakias: TLPs).

\section{MATERIALS AND METHODS}

\section{Tissue samples}

Tumours of the tongue or premalignant lesions of the tongue (histologically diagnosed as TLPs), with patient-matched normal epithelium where available, were obtained at the time of surgical resection at Chiba University Hospital after the patient's informed consent was obtained under a protocol reviewed and approved by the institutional review board of Chiba University. The resected tissues were divided into two parts, one of which was frozen immediately after careful removal of the surrounding normal tissues and stored at $-80^{\circ} \mathrm{C}$ until RNA isolation; the second part was fixed in $10 \%$ buffered formaldehyde solution for pathologic 
diagnosis and for immunohistochemical staining. Histopathologic diagnosis of each neoplastic tissue was performed according to the World Health Organisation criteria by the Department of Pathology, Chiba University Hospital. Clinicopathologic staging was determined by the TNM classification of the International Union against Cancer. All patients had SCC or leukoplakia that was histologically confirmed, and tumour samples were checked to ensure that tumour tissue was present in more than $80 \%$ of the specimens.

\section{RNA isolation}

Total RNA was extracted using Trizol Reagent (Invitrogen Life Technologies, Carlsbad, CA, USA) according to the manufacturer's instructions. Each of extracted RNA was stored separately at $-80^{\circ} \mathrm{C}$ until use.

\section{In-house cDNA microarray analysis}

In total, $20 \mu \mathrm{g}$ of purified total RNA obtained from four randomly selected patients with TSCC was subjected to microarray analysis. Samples of total RNA from these patients were similarly purified and pooled to serve as controls. A cDNA microarray chip consisting of 2304 cDNAs was created as previously described (Moriya et al, 2003). The cDNA microarray was based on an oligocapped cDNA library of the OSCC tissues, oral normal tissues and OSCC-derived cell lines: unique clones (2304) were selected from about 4608 sequenced clones in the library. cDNA microarray analysis was performed as described previously (Yoshikawa et al, 2000). Briefly, Cy3-dUTP or Cy5-dUTP (Amersham Biosciences UK Ltd, UK) was incorporated during reverse transcription of $20 \mu \mathrm{g}$ of purified total RNA, primed by an oligo dT primer. Different fluorescent-labelled probes from each tumour and normal tissues were mixed and applied to the cDNA microarray after incubation at $65^{\circ} \mathrm{C}$ overnight in a humidified atmosphere. Two hybridyzations were carried out for each experiments in which the fluorescent dyes were switched during cDNA synthesis. Each pair of corresponding probes was hybridysed to a separate microarray. The fluorescent images of hybridised microarrays were scanned with a fluorescence laser confocal slide scanner (Scan Array Lite, Packard Bio Science, Billerica, MA, USA). Images were analysed with microarray analysis software (QuantArray, Packard Bio Science), according to the manufacturer's instructions. Spots were only included if their raw fluorescence intensities at least 1.5 times the local background.

\section{Real-time quantitative RT-PCR}

qRT-PCR was used to examine the expression status of the 10 genes whose function is known.
The cDNA templates for $\mathrm{qRT}$ - PCR were synthesised from the four RNA samples of TSCCs used in the microarray analysis, and two additional RNA samples were prepared for the evaluation of Rabla gene expression. The nucleotide sequences of gene-specific primers and predicted sizes of the resulting PCR products for qRT - PCR are shown in Table 1. qRT - PCR was performed with a single method using a LightCycler FastStart DNA Master SYBR Green I kit (Roche Diagnostics GmbH, Mannheim, Germany). For preparing the standard curve, $1.5 \mu \mathrm{g}$ of total RNA from normal oral tissue was reverse transcribed with Superscript ${ }^{\mathrm{TM}}$ reverse transcriptase (Life Technologies, Grand Island, NY, USA) and oligo-d $(\mathrm{T})_{12-18}$ primer, after which serial dilutions were made corresponding to cDNA transcribed from $300,30,3.0$, and $0.3 \mathrm{ng}$ of total RNA. The PCR reactions using a LightCycler (Roche) apparatus were carried out in a final volume of $20 \mu \mathrm{l}$ of reaction mixture consisting of $2 \mu \mathrm{l}$ of FirstStart DNA Master SYBR Green I mix (Roche), $3 \mathrm{mM} \mathrm{MgCl}$, and $0.2 \mu$ l of the primers, according to the manufacturer's instructions. The reaction was performed as per the manufacturer's instructions. The transcript amount for genes were estimated from the respective standard curves and normalised to the glyceraldehyde-3-phosphate dehydrogenase (GAPDH) transcript amount determined in corresponding samples.

\section{Immunohistochemistry}

Out of the differentially upregulated genes, one gene (Rabla) was singled out as a valid candidate biomarker of TSCC. In totl, 54 pairs of tongue carcinoma and matched normal tissue and 13 TLP paraffin-embedded tissue samples were used for immunohistochemistry to examine Rab1A protein expression status. Sections $(4 \mu \mathrm{m})$ were deparaffinised, unmasked Rab1A antigen by microwave treatment in $10 \mathrm{~mm}$ sodium citrate buffer ( $\mathrm{pH} 6)$ and rinsed three times in PBS solution. After quenching the endogenous peroxidase activity in $0.5 \% \mathrm{H}_{2} \mathrm{O}_{2}$ for $30 \mathrm{~min}$, the sections were reacted with Rab1A polyclonal antibody (Santa Cruz Biotechnology, Santa Cruz, CA, USA) at a dilution of $1: 50$ overnight at room temperature in a humidified atmosphere. Upon incubation with the primary antibody, the specimens were washed three times in phosphate-buffered saline and treated with ENVISION reagent (DAKO JAPAN Inc., Kyoto, Japan) followed by colour development in 3,3'-diaminobenzidine tetrahydrochloride (DAKO). Finally, the slides were lightly counterstained with haematoxylin, dehydrated with ethanol, cleaned with xylene, and mounted. As a negative control, duplicate sections were immunostained without exposure to primary antibodies. To quantitate the state of Rab1A protein expression, the mean percentage of positive tumour cells was determined in at least five random fields at $\times 400$ magnification in each section. The intensity of the

Table I Primer pairs for quantitative RT-PCR analysis

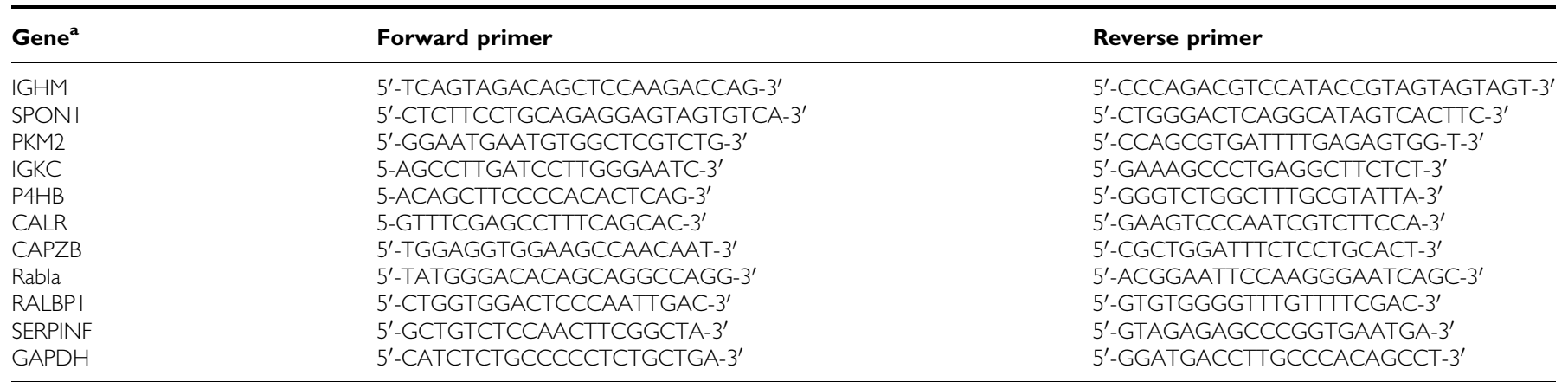

${ }^{a} \mid G H M=$ immunoglobulin heavy constant $\mathrm{mu} ; \mathrm{SPONI}=$ spondin I; PKM2 = pyruvate kinase muscle type 2; IGKC = immunoglobulin kappa constant region; $\mathrm{P} 4 \mathrm{HB}=$ procollagen-proline,2-oxoglutarate-4-dioxygenase,beta; $C A L R=$ calreticulin; $C A P Z B=$ capping protein muscle Z-line, beta; RALBPI = rala-binding protein I; SERPINF = pigment epithelium-derived factor. 
Rab1A-immunoreaction was scored as follows: $1+$, weak; $2+$, moderate; and $3+$, intense. The percentage of positive tumour cells and the staining intensity then were multiplied to produce a Rab1A-immunohistochemical staining score. Cases with a Rab1A score $>76.17$ (the highest score of normal tissue) were defined as positive. These judgments were made by two independent pathologists, neither of whom had any knowledge or information pertaining to the patients' clinical status. Any discrepancy in the scoring of the slides was resolved jointly by the pathologists by discussion and a consensus observation was recorded afterward. Statistical significance was evaluated by the Fisher's exact test, or Mann - Whitney's U-test.

\section{RESULTS}

\section{Identification of candidate TSCC target genes}

In the search for genes involved in the development of human TSCC, we compared gene expression between tumorous and normal tongue tissue samples in four patients with TSCC. The comparison between tumours and normal tissues showed that 16 genes were upregulated in all cases (Table 2).

\section{Validation of the in-house cDNA microarray results}

To further validate the cDNA array approach, we performed qRTPCR on the 10 genes with known function (Table 1) to analyse mRNA expression level in the four TSCC cases examined by the cDNA microarray analysis. We found that all the 10 genes showed a significant upreguration in tumour tissues (Figure 1A, B) when compared to corresponding normal tissues, although the fold change in the expression level was not exactly same between the microarray analysis and $\mathrm{qRT}-\mathrm{PCR}$. In addition, there was a statistically significant difference of the Rabla gene expression status between TSCCs $(n=6)$ and matched normal tongue tissues (Wilcoxon signed-rank test, $P=0.0277$; Figure 1B). Futhermore, all the TSCCs showing upregulation of the Rab1a mRNA expression revealed overexpression of the protein.

\section{Expression of Rab1A in malignant and premalignant lesions of the tongue}

In total, 54 patients with TSCC were identified for whom there was adequate histologic material available for immunohistochemical analysis. The correlation between the clinicopathologic characteristics of patients with TSCC and Rab1A expression status is summarised in Table 3. All normal oral mucosa specimens had no or significant downregulation of Rab1A expression and were considered as Rab1A-negative (Fisher's exact test). Among the tumours examined, 53 of 54 cases (98\%) had a Rab1Aimmunoreaction in the cytoplasm of the tumour cells (Table 3 ). However, there was no statistically significant differences between Rab1A expression and the clinicopathologic features (Table 3). Interestingly, 12 of 13 TLPs (93\%) were considered Rab1Apositive. Representative results for Rab1A protein expression in normal oral tissue, TLP, and primary TSCC are shown in Figure 2. The Rab1A immunohistochemistry scores for normal tissues, TLPs, and TSCCs ranged from 0 to 76.2 (mean, 31.9), 73.5 to 182.9 (mean, 121.4), and 60.2 to 221.8 (mean, 148.0), respectively. The Rab1A expression levels in primary TSCCs and TLPs were significantly higher than those in normal oral tissues (MannWhitney's $U$-test, $P<0.0001$; Figure 3 ). There was also a significant difference in RAB1A-IHC scores between TSCCs and TLPs (Mann-Whitney's $U$-test, $P=0.0298$; Figure 3).

\section{DISCUSSION}

Considerable evidence has been reported that the identification of novel disease relevant targets/pathways and tumour classification/ stratification can be achieved by microarray-based gene expression profiling. In this context, there are numerous studies of the use of disease profiles in tumours of clinically relevant subgroups, including the brain (Sallinen et al, 2000), oesophagus (Lu et al, 2001), lung (Wang et al, 2000), gastrointestinal tract (El-Rifai et al, 2001; Inoue et al, 2002), thyroid (Wasenius et al, 2003), breast (Assersohn et al, 2002; Ellis et al, 2002), leukaemia (Moos et al, 2002), colon (Williams et al, 2003), prostate (Bull et al, 2001). There are also several studies to classify OSCCs using commercially available cDNA microarrays (Ohyama et al, 2000; Alevizos et al, 2001; Kuo et al, 2002; Vigneswaran et al, 2005). We recently developed an in-house cDNA microarray derived from our oligocapped human cDNA library prepared from noncancerous and cancerous tongue tissues, and oral cancer cell lines (Moriya et al, 2003).

The first step in the present study was to identify gene(s) that were differentially expressed in TSCC compared with normal tongue epithelium using the in-house cDNA microarray system. Defining a 2.0-fold difference as the threshold, 16 genes of interest were identified from four TSCC specimens. As shown in Table 2, 13 were known genes and three were unknown genes. In total, 10 genes (IGHM, SPON1, PKM2, IGKG, P4HB, CALR, CAPZB, RALBP1, SERPINF1, and Rab1a) with known molecular function

Table 2 Genes with high expression levels in TSCCs

\begin{tabular}{|c|c|c|c|c|}
\hline UniGene ID & Gene & Molecular function & Chromosomal position & Fold change $^{a}$ \\
\hline Hs.297962 & Hypothetical protein & Unknown & Chromosomes 19 & 10.79 \\
\hline Hs. $|5326|$ & IGHM & Immune system & $14 q 32.33$ & 9.02 \\
\hline Hs.5387 & SPONI & Extracellular matrix protein & ||p|4-pl5.2 & 5.92 \\
\hline Hs. 198281 & PKM2 & Catalyse the production of phosphoenolpyruvate & $15 q 22$ & 5.66 \\
\hline Hs.406565 & IGKC & Immune system & $2 p 12$ & 5.25 \\
\hline Hs.903I 5 & KIAA0007 & Unknown & $2 p 23.2$ & 4.61 \\
\hline Hs.55098 & C3orf6 & Unknown & Chromosomes 3 & 3.24 \\
\hline Hs.4343I & Hypothetical protein & Unknown & $6 p 22.3$ & 2.92 \\
\hline $\mathrm{gb} \mid \mathrm{B} \times 442293^{\mathrm{b}}$ & Unknown & Unknown & Unknown & 2.82 \\
\hline Hs.83286 & Hypothetical protein MGC33424 & Unknown & Unknown & 2.61 \\
\hline Hs.4I0578 & $\mathrm{P} 4 \mathrm{HB}$ & Protein disulphide isomerase & $17 q 25$ & 2.57 \\
\hline Hs.353170 & CALR & Calciumstrage, transcriptin co-repressor & 19pl3.3-pl3.2 & 2.57 \\
\hline Hs.3334I7 & CAPZB & Actin binding & |pG6.| & 2.45 \\
\hline Hs.227327 & Rabla(RAS oncogene family) & RAB small monomeric GTP ase & $2 p \mid 4$ & 2.27 \\
\hline Hs.75447 & RALBPI & GTPase activator & |spll.3 & 2.22 \\
\hline Hs. 173594 & 3ERPINFI & Serine protease inhibitor & |7pl3.| & 2.16 \\
\hline
\end{tabular}

${ }^{a}$ Fold over-expression for rnicroarray data based on ratio of fluorescence for TSCCs compared to normal control. ${ }^{b}$ GenBank Accession Number. 

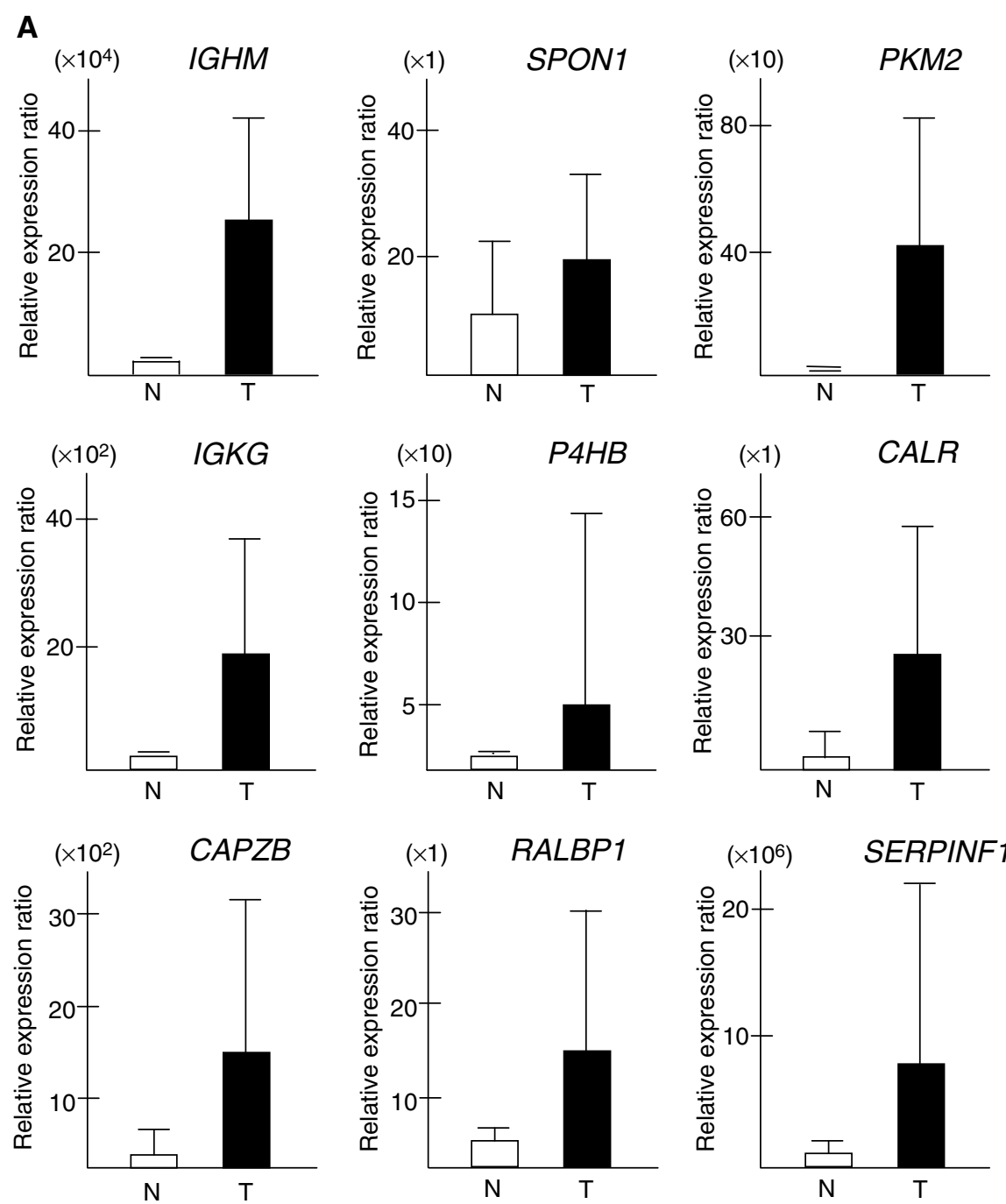

B

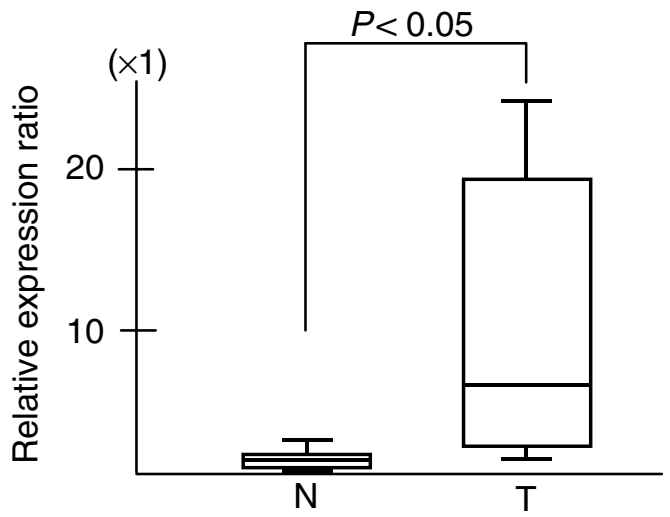

Figure I Validation of cDNA microarray data by real-time quantitative RT-PCR (qRT-PCR). (A) Nine genes with known molecular function were subjected to qRT-PCR in the mRNA from four TSCCs and four samples of the corresponding normal tissue used in the microarray analysis. A significant upregulation was evident in all the genes evaluated. (B) A significant higher expression of the Rab l a gene was detected in primary TSCCs $(n=6)$ than that in the six corresponding normal tissues $(P=0.0277$. Wilcoxon signed-rank test). Relative expression ratio is defined as the expression levels of the gene to those of the internal reference gene, GAPDH. The assays were carried out in triplicate and means \pm standard deviations were plotted.

were subjected to qRT - PCR analysis, and they were confirmed to be upregulated in the TSCCs examined, when compared to the corresponding normal tissues. So far, none of these genes or their corresponding proteins have been attributed directly to the development of TSCC, suggesting that these genes are novel potential targets for this disease.

Immunoglobulin heavy constant $m u$ (IGHM) encodes the heavy chain unique to IgM that is on chromosome 14q32.33. Chromo- 
Table 3 Correlation between Rabla expression and clinicopathologic features in human oral cancer

\begin{tabular}{|c|c|c|c|c|}
\hline \multirow[b]{2}{*}{ Clinical classification } & \multirow[b]{2}{*}{ Total } & \multicolumn{3}{|c|}{$\begin{array}{l}\text { Result of immunostaining } \\
\text { (no. of patients, \%) }\end{array}$} \\
\hline & & RablA(+) & $\operatorname{RabIA(-)}$ & $P$-value \\
\hline \multicolumn{5}{|l|}{ Age at surgery } \\
\hline$<60$ & 27 & $27(100)$ & $0(0)$ & 0.24074 \\
\hline $60-70$ & 14 & $14(100)$ & $0(0)$ & \\
\hline$\geqslant 70$ & 13 & $12(92)$ & I (8) & \\
\hline \multicolumn{5}{|l|}{ Gender } \\
\hline Male & 35 & $34(97)$ & I (3) & I \\
\hline Female & 19 & $19(100)$ & $0(0)$ & \\
\hline \multicolumn{5}{|l|}{$T$ of primary tumor } \\
\hline $\mathrm{TI}$ & 6 & $6(100)$ & $0(0)$ & 0.33333 \\
\hline T2 & 18 & $18(100)$ & $0(0)$ & \\
\hline T3 & 18 & $18(100)$ & $0(0)$ & \\
\hline T4 & 12 & II (92) & I (8) & \\
\hline \multicolumn{5}{|l|}{$N$ of regional lymph node } \\
\hline $\mathrm{K}(+)$ & 40 & $39(98)$ & I (2) & I \\
\hline$K(-)$ & 14 & $14(100)$ & $0(0)$ & \\
\hline \multicolumn{5}{|l|}{ Stage } \\
\hline I & 5 & $5(100)$ & $0(0)$ & । \\
\hline$\|$ & 5 & $5(100)$ & $0(0)$ & \\
\hline III & 16 & $16(100)$ & $0(0)$ & \\
\hline IV & 28 & $27(96)$ & I (4) & \\
\hline \multicolumn{5}{|l|}{ Histopathological type } \\
\hline Well differentiated & 35 & $34(97)$ & I (3) & । \\
\hline Moderately differentiated & 9 & $9(100)$ & $0(0)$ & \\
\hline Poorly differentiated & 10 & $10(100)$ & $0(0)$ & \\
\hline Leukoplakias & 13 & $12(92)$ & $1(8)$ & \\
\hline
\end{tabular}

some rearrangements of this band affect the $A K T 1$ gene, the protooncogene of the viral oncogene $v$-akt (Staal et al, 1988).

Spondin 1 (SPON1) is an extracellular matrix protein. Nagase screened human brain cDNAs for the potential to encode proteins that are at least $50 \mathrm{kDa}$, which they called KIAA0762 (Nagase et al, 1998). It is similar to rat F-spondin; thus, this gene may have a role in the growth and guidance of axons. They also indicated that the SPON1 gene is on chromosome 11p15.2. Nearby are the MUC2 and MUC6 genes (11p15) that might be related to lymph node metastasis (Nishiumi et al, 2003).

Pyruvate kinase muscle type 2 (PKM2) is known as ATP:pyruvate phosphotransferase and occurs in four isozymic forms (L, R, M1, M2). Tsutsumi et al (1988) isolated and sequenced two overlapping clones covering the entire coding sequence of PKM2. Kress et al (1998) indicated that mRNA level of PKM2 is increased in human colorectal cancers in comparison to the corresponding normal tissues.

IGKG encode immunoglobulin kappa chain constant region. Lenormand et al (1991) reported 20 of the 25 patients with B-cell chronic lymphocytic leukaemia (B-CELL) showed IGKC rearrangement.

$\mathrm{P} 4 \mathrm{HB}$ is involved in hydroxylation of prolyl residues in preprocollagen. Tasanen et al (1988) isolated genomic clones for the human gene coding for this multifunctional protein. Pajunen et al $(1987,1988)$ assigned the gene to chromosome 17 , specifically, $17 \mathrm{q} 23-\mathrm{q} 25$. The chromosomal aberration of this region may be involved in carcinogenesis in the tylosis with oesophageal cancer (TOC) (Shahabi et al, 2004) and liver cancer (Midorikawa et al, 2004).

CALR is a multifunctional protein that acts as a major $\mathrm{Ca}(2+)$ binding (storage) protein in the lumen of the endoplasmic
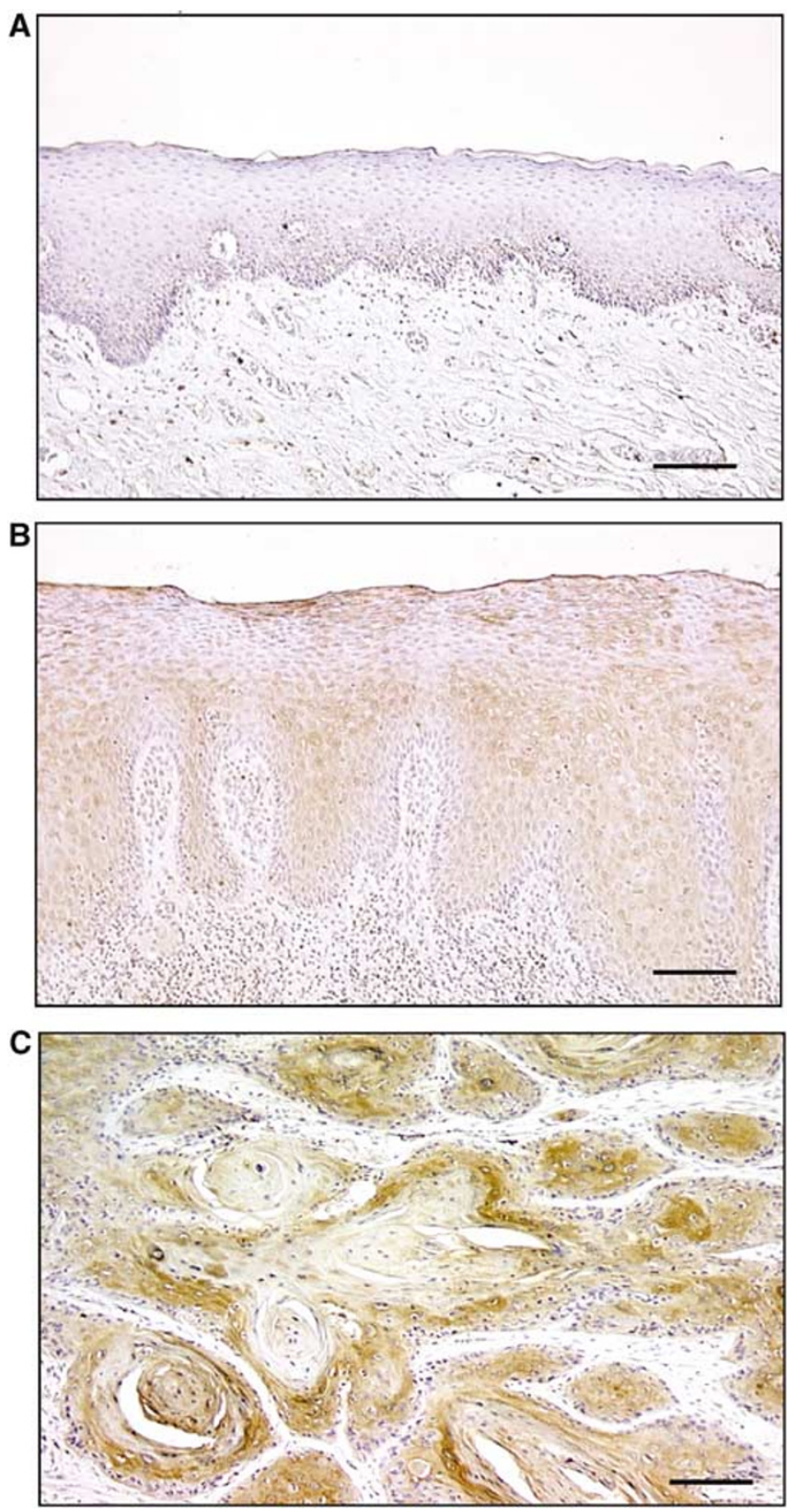

Figure 2 Immunohistochemical staining of Rab|A. (A) Normal tongue epithelium tissue shows weak expression of Rab|A protein. (B) Rab IApositive case of TLP. The immunoreaction is slightly enhanced in the basal layer. (C) TSCC tissue shows strong cytoplasmic staining of the tumour cells. Original magnification, $\times 40$. Bar $=100 \mu \mathrm{m}$.

reticulum. Accumulation of CALR protein is observed in a few cancers, including breast cancer (Franzen et al, 1996) and hepatocellular carcinoma (Yoon et al, 2000).

Capping protein muscle Z-line, beta (CAPZB) is a member of the F-actin capping protein family. Barron-Casella et al (1995) isolated cDNAs homologues for the beta subunit of chicken Cap Z from human retinal cDNA libraries. This gene encodes the beta subunit of the barbed-end actin binding protein that regulates growth of the actin filament by capping the barbed end of growing actin filaments. Those investigators mapped the CAPZB gene to $1 \mathrm{p} 36.1$, which has frequent loss of heterozygosity observed in neuroblastomas (Fong et al, 1989) and in oropharyngeal epithelial carcinomas (Grati et al, 2000). 


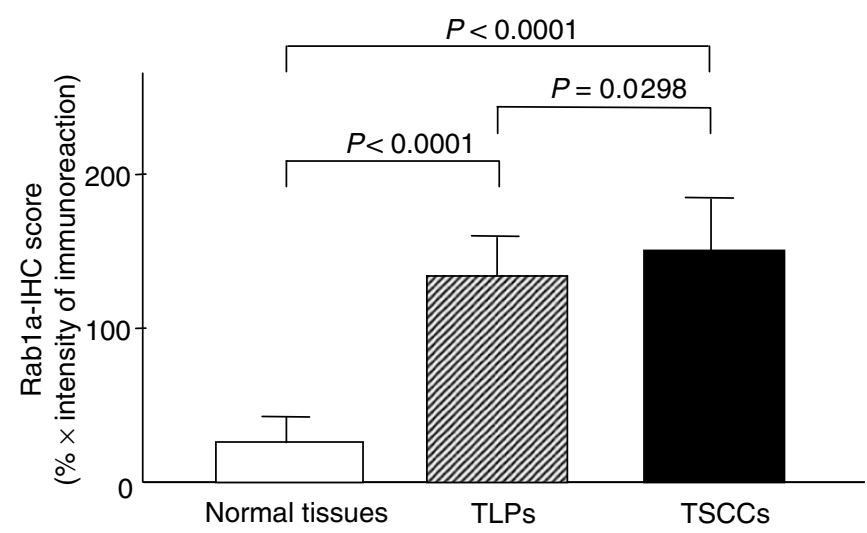

Figure 3 State of Rabla protein expression in normal oral tissues $(n=54)$, TLPs $(n=13)$, and TSCCs $(n=54)$. The Rab|A-|HC scores were calculated as follows: Rab|A-IHC=the mean percentage of positive tumour cells $\times$ staining intensity. Rab IA protein expressions in TLPs and TSCCs were significantly higher than in normal oral tissues $(P<0.0001$, Mann-Whitny's U-test). There was also slight difference between TLPs and TSCCs $(P=0.0268$, Mann-Whitny's $U$-test). Results are expressed as means \pm s.d.

Jullien-Flores et al (1995) obtained a cDNA encoding RALBP1, which they termed RLIP76. RALBP1 participate in signalling for a variety of cellular processes and are regulated in part by guanine nucleotide dissociation stimulators, and coordinate the cellular actions of activated EGF receptors and Ral-GTPases. The activity of RALBP1 may contribute to the drug-resistant of small-cell lung cancer (SCLC) (Singhal et al, 2003).

Serpins are a group of serine protease inhibitors, some of which have also been reported to exhibit neurotrophic activity. In studies aimed at identifying antiangiogenic factors in the eye, Dawson et al (1999) identified SERPINF1. SERPINF1 may serve as a multifunctional antitumour agent in neuroblastomas, inhibiting angiogenesis (Crawford et al, 2001).

$R a b 1 a$ is a member of the Ras oncogene superfamily. Rab proteins represent a family of at least 30 different Ras-like GTPases that function in the processes by which membrane vesicles identify and/or fuse with their targets (Zahraoui et al, 1989; Ferro-Novick and Novick, 1993; Novick and Brennwald, 1993; Jaakko et al, 1995), suggesting that abnormal regulation of membrane traffic, which is one of the important cellular processes, may lead to tumorigenesis. Thus, we have selected the Rab1a gene for further

\section{REFERENCES}

Alevizos I, Mahadevappa M, Zhang X, Ohyama H, Kohno Y, Posner M, Gallagher GT, Varvares M, Cohen D, Kim D, Kent R, Donoff RB, Todd R, Yung CM, Warrington JA, Wong DT (2001) Oral cancer in vivo gene expression profiling assisted by laser capture microdissection and microarray analysis. Oncogene 20: 6196-6204

Assersohn L, Gangi L, Zhao Y, Dowsett M, Simon R, Powles TJ, Liu ET (2002) The feasibility of using fine needle aspiration from primary breast cancers for cDNA microarray analyses. Clin Cancer Res 8: 794-801

Barron-Casella EA, Torres MA, Scherer SW, Heng HH, Tsui LC, Casella JF (1995) Sequence analysis and chromosomal localization of human cap Z. J Biol Chem 270: 21472 -21479

Boyle P, Macfarlane GJ, Zheng T, Maisonneuve P, Evstifeeva T, Scully C (1992) Recent advances in epidemiology of head and neck cancer. Curr Opin Oncol 4: 471-477

Bull JH, Ellison G, Patel A, Muir G, Walker M, Underwood M, Khan F, Paskins L (2001) Identification of potential diagnostic markers of prostate cancer and prostatic intraepithelial neoplasia using cDNA microarray. Br J Cancer 84: 1512 - 1519 investigation. To clarify its relative contribution to tongue carcinogenesis, we further investigated the protein expression in a series of TSCCs and TLPs. We detected a comparatively strong tumour cell-localised cytoplasmic Rab1A-immunoreaction, raising the possibility that the gene product(s) may serve as a diagnostic marker of tongue cancer. By evaluating the Rab1A immunohistochemistry scores using the Mann-Whitney's $U$-test, significant Rab1A upregulation was evident not only in the primary TSCCs $(P<0.0001$, TSCC $v s$ corresponding normal tissues) but also in the TLPs $(P<0.0001$, TLPs $v s$ corresponding normal tissues) when compared with normal tissues. In addition, the levels of Rab1A expression in SCCs tended to be higher than that in TLPs $(P=0.0268)$, suggesting that Rab1A expression is not only a precipitous event during tongue carcinogenesis but also an important candidate for the progression of TSCCs. In addition, whereas most corresponding normal tongue squamous cells appeared not to express Rab1A, faint but positive cytoplasmic staining was detected in a basal layer of tongue epithelial cells of matched normal tongue tissue (Figure 2A). One possible explanation is that Rab1A could be associated with proliferation state (even of normal epithelium). Thus, it might be a secondary event not directly associated with cancer causes. At present, it is unclear why basal layer of normal epithelium showed Rab1A protein stimulation. Further studies on a large series of patients and in samples of a proliferative, noncancererous disorder, will provide more accurate information about the involvement of Rab1A expression in the development of TSCC.

Overall, we found expression profile changes that suggest genetic alterations not only favouring a transformed epithelial cell per se but also having the capabilities of modulating the immediate microenvironment, which may aid tumour progression in the tongue. The present study identified aberrant Rab1A expression in premalignant and malignant tissues, suggesting its appearance and overexpression in TLPs as a possible biologic marker of imminent progression. The association of genes identified in our study with clinical variables and gaining an understanding of the regulation of their expression will aid in determining their potential use as molecular markers in this cancer.

\section{ACKNOWLEDGEMENTS}

We thank LC Charters for editing this manuscript. This study was partly supported by the grant-in-Aid for Scientific Research from the Ministry of Education, Culture, Sports, Science and Technology, Japan.
Crawford SE, Stellmach V, Ranalli M, Huang X, Huang L, Volpert O, De Vries GH, Abramson LP, Bouck N (2001) Pigment epithelium-derived factor (PEDF) in neuroblastoma: a multifunctional mediator of Schwann cell antitumor activity. J Cell Sci 24: 4421-4428

Dawson DW, Volpert OV, Gillis P, Crawford SE, Xu H-J, Benedict W, Bouck NP (1999) Pigment epithelium-derived factor: a potent inhibitor of angiogenesis. Science 285: 245-248

DeRisi J, Penland L, Brown PO, Bittener ML, Meltzer PS, Chen Y, Su YA, Trent JM (1996) Use of cDNA microarray to analyse gene expression patterns in human cancer. Nat Genet 14: 457-460

Ellis M, Davis N, Coop A, Liu M, Schumaker L, Lee RY, Srikanchana R, Russell CG, Singh B, Miller WR, Stearns V, Pennanen M, Tsangaris T, Gallagher A, Liu A, Zwart A, Hayes DF, Lippman ME, Wang Y, Clarke R (2002) Development and validation of a method for using breast core needle biopsies for gene expression microarray analyses. Clin Cancer Res 8: $1155-1166$

El-Rifai W, Frierson Jr HF, Harper JC, Powell SM, Knuutila S (2001) Expression profiling of gastric adenocarcinoma using cDNA array. Int $J$ Cancer 92: $832-838$ 
Fearon ER, Vogelstein B (1990) A genetic model for colorectal tumrigenesis. Cell 61: 759-767

Ferro-Novick S, Novick P (1993) The role of GTP-binding protein in transport along the exocytic pathway. Ann Rev Cell Biol 2: 575-599

Fong CT, Dracopoli NC, White PS, Merrill PT, Griffith RC, Housman DE, Brodeur GM (1989) Loss of heterozygosity for the short arm of chromosome 1 in human neuroblastomas: correlation with $\mathrm{N}$-myc amplification. Proc Natl Acad Sci USA 86: $3753-3757$

Franzen B, Linder S, Alaiya AA, Eriksson E, Uruy K, Hirano T, Okuzawa K, Auer G (1996) Analysis of polypeptide expression in benign and malignant human breast lesions: down-regulation of cytokeratins. $\mathrm{Br} \mathrm{J}$ Cancer 74: $1632-1638$

Grati FR, Sirchia SM, Garagiola I, Sironi E, Galioto S, Rossella F, Serafini P, Dulcetti F, Bozzetti A, Brusati R, Simoni G (2000) Losses of heterozygosity in oral and oropharyngeal epithelial carcinomas. Cancer Genet Cytogenet 118: 57-61

Inoue H, Matsuyama A, Mimori K, Ueo H, Mori M (2002) Prognostic score of gastric cancer determined by cDNA microarray. Clin Cancer Res 8: $3475-3479$

Jaakko S, Ulla L, Bruno G (1995) Localization of the small GTP-binding protein rablp to early compartments of the secretory pathway. J Cell Sci 108: $1541-1552$

Jullien-Flores V, Dorseuil O, Romero R, Letourneur F, Saragosti S, Berger R, Tavitian A, Gacon G, Camonis JH (1995) Bridging Ral GTPase to Rho pathways: RLIP76, a Ral effector with CDC42/Rac GTPase-activating protein activity. J Biol Chem 270: 22473-22477

Kress S, Stein A, Maurer P, Weber B, Reichert J, Buchmann A, Huppert P, Schwarz M (1998) Expression of hypoxia-inducible genes in tumor cells. J Cancer Res Clin Oncol 124: 315-320

Kuo WP, Whipple ME, Sonis ST, Ohno-Machado L, Jenssen TK (2002) Gene expression profiling by DNA microarrays and its application to dental research. Oral Oncol 38: 650-656

Lenormand B, Ghanem N, Tilly H, Boussemart C, Monconduit M, Piguet H, Lefranc G, Lefranc MP (1991) Rearrangements of immunoglobulin light and heavy chain genes and correlation with phenotypic markers in B-cell chronic lymphocytic leukemia. Leukemia 5: 928-936

Lu J, Liu Z, Xiong M, Wang Q, Wang X, Yang G, Zhao L, Qiu Z, Zhou C, Wu $M$ (2001) Gene expression profile changes in initiation and progression of squamous cell carcinoma of esophagus. Int J Cancer 91: 288-294

Macfarlane GJ, Zheng T, Marshall JR, Boffetta P, Niu S, Brasure J, Merletti F, Boyle P (1995) Alcohol, tobacco, diet and the risk of oral cancer: a pooled analysis of three case-control studies. Eur J Cancer B Oral Oncol 31: $181-187$

Marshall CJ (1991) Tumor suppressor genes. Cell 64: 313-326

Mashberg A, Boffetta P, Winkelman R, Garfinkel L (1993) Tobacco smoking, alcohl drinking, and cancer of the oral cavity and orpharynx among U.S. veterans. Cancer 72: 1369-1375

Midorikawa Y, Tsutsumi S, Nishimura K, Kamimura N, Kano M, Sakamoto H, Makuuchi M, Aburatani H (2004) Distinct chromosomal bias of gene expression signatures in the progression of hepatocellular carcinoma. Cancer Res 64: 7263-7270

Moos PJ, Raetz EA, Carlson MA, Szabo A, Smith FE, Willman C, Wei Q, Hunger SP, Carroll WL (2002) Identification of gene expression profiles that segregate patients with childhood leukemia. Clin Cancer Res 8: $3118-3130$

Moriya T, Seki N, Shimada K, Kato M, Yakushiji T, Nimura Y, Uzawa K, Takiguchi M, Tanzawa H (2003) In-house cDNA microarray analysis of gene expression profiles involved in SCC cell lines. Int J Mol Med 12: $429-435$

Nagase T, Ishikawa K, Suyama M, Kikuno R, Miyajima N, Tanaka A, Kotani $\mathrm{H}$, Nomura N, Ohara O (1998) Prediction of the coding sequences of unidentified human genes. XI. The complete sequences of 100 new cDNA clones from brain which code for large proteins in vitro. DNA Res 30: $277-286$

Nishiumi N, Abe Y, Inoue Y, Hatanaka H, Inada K, Kijima H, Yamazaki H, Tatematsu M, Ueyama Y, Iwasaki M, Inoue H, Nakamura M (2003) Use of $11 \mathrm{p} 15$ mucins as prognostic factors in small adenocarcinoma of the lung. Clin Cancer Res 15: 5616-5619

Novick P, Brennwald P (1993) Friends and Family: the role of the Rab GTPases in vesicular traffic. Cell 75: 597-601
Ohyama H, Zhang X, Kohno Y, Alevizos I, Posner M, Wong DT, Todd R (2000) Laser capture microdissection-generated target sample for highdensity oligonucleotide array hybridization. Biotechniques 29: 530-536

Pajunen L, Myllyla R, Helaakoski T, Pihlajaniemi T, Tasanen K, Hoyhtya M, Tryggvason K, Solomon E, Kivirikko KI (1987) Assignment of the gene coding for both the beta-subunit of prolyl 4-hydroxylase and protein disulphide isomerase to human chromosome region 17q23-25. Cytogenet Cell Genet 46: 674

Pajunen L, Myllyla R, Helaakoski T, Pihlajaniemi T, Tasanen K, Hoyhtya M, Tryggvason K, Solomon E, Kivirikko KI (1988) Assignment of the gene coding for both the beta-subunit of prolyl 4-hydroxylase and the enzyme disulfide isomerase to human chromosome region 17p11-qter. Cytogenet Cell Genet 47: $37-41$

Perkin DM, Pisani P, Ferlay J (1993) Estimates of the worldwide incidence of eighteen major cancers in 1985. Int J Cancer 54: 549-606

Sallinen SL, Sallinen PK, Haapasalo HK, Helin HJ, Helen PT, Schraml P, Kallioniemi OP, Kononen J (2000) Identification of differentially expressed genes in human gliomas by DNA microarray and tissue chip techniques. Cancer Res 60: 6617-6622

Schena M, Shalon D, Davis RW, Brown PO (1995) Quantitative monitoring of gene expression patterns with a complementary DNA microarray. Science 270: $467-470$

Scully C, Field JK, Tanzawa H (2000) Genetic aberrations in oral or head and neck squamous cell carcinoma (SCCHN): 1. Carcinogen metabolism, DNA repair and cell cycle control. Oral Oncol 36: 256-263

Shahabi M, Noori Daloii MR, Langan JE, Rowbottom L, Jahanzad E, Khoshbin E, Taghikhani M, Field JK, Risk JM (2004) An investigation of the tylosis with oesophageal cancer (TOC) locus in Iranian patients with oesophageal squamous cell carcinoma. Int J Onco 25: 389-395

Singhal SS, Singhal J, Sharma R, Singh SV, Zimniak P, Awasthi YC, Awasthi $S$ (2003) Role of RLIP76 in lung cancer doxorubicin resistance: I. The ATPase activity of RLIP76 correlates with doxorubicin and 4-hydroxynonenal resistance in lung cancer cells. Int J Oncol 22: 365-375

Staal SP, Huebner K, Croce CM, Parsa NZ, Testa JR (1988) The AKT1 proto-oncogene maps to human chromosome 14, band q32. Genomics 2: 96-98

Tasanen K, Parkkonen T, Chow LT, Kivirikko KI, Pihlajaniemi T (1988) Caracterization of the human gene for a polypeptide that acts both as the beta-subunit of prolyl 4-hydroxylase and as protein disulfide isomerase. J Biol Chem 263: $16218-16224$

Tsutsumi H, Tani K, Fujii H, Miwa S (1988) Expression of L- and M-type pyruvate kinase in human tissues. Genomics 2: 86-89

Vigneswaran N, Wu J, Sacks P, Gilcrease M, Zacharias W (2005) Microarray gene expression profiling of cell lines from primary and metastatic tongue squamous cell carcinoma: possible insights from emerging technology. J Oral Pathol Med 34: 77-86

Wang T, Hopkins D, Schmidt C, Silva S, Houghton R, Takita H, Repasky E, Reed SG (2000) Identification of genes differentially over-expressed in lung squamous cell carcinoma using combination of cDNA subtraction and microarray analysis. Oncogene 19: 1519-1528

Wasenius VM, Hemmer S, Kettunen E, Knuutila S, Franssila K, Joensuu H (2003) Hepatocyte growth factor receptor, matrix metalloproteinase-11, tissue inhibitor of metalloproteinase-1, and fibronectin are up-regulated in papillary thyroid carcinoma: a cDNA and tissue microarray study. Clin Cancer Res 9: 68-75

Williams NS, Gaynor RB, Scoggin S, Verma U, Gokaslan T, Simmang C, Fleming J, Tavana D, Frenkel E, Becerra C (2003) Identification and validation of genes involved in the pathogenesis of colorectal cancer using cDNA microarrays and RNA interference. Clin Cancer Res 9: $931-946$

Yoon GS, Lee H, Jung Y, Yu E, Moon HB, Song K, Lee I, Weaver SA, Schaefer AL, Dixon WT (2000) Nuclear matrix of calreticulin in hepatocellular carcinoma. Cancer Res 60: 1117-1120

Yoshikawa T, Nagasugi Y, Azuma T, Kato M, Sugano S, Hashimoto K, Masuho Y, Muramatsu M, Seki N (2000) Isolation of novel mouse genes differentially expressed in brain using cDNA microarray. Biochem Biophys Res Commun 275: 532-537

Zahraoui A, Touchot N, Chardin P, Tavitian A (1989) The human Rab genes encode a family of GTP-binding proteins related to yeast YPT1 and SEC4 products involved in secretion. J Biol Chem 264: 12394-12401 